\title{
Ethical Perspectives on Production Diseases in Farm Animals
}

\author{
By Peter Sandøe
}

Centre for Bioethics and Risk Assessment, The Royal Veterinary and Agricultural University, Frederiksberg, Denmark.

Over the last 50 years animal production in the Western world has become increasingly efficient. In many ways this market-driven development can be viewed as a success story. Thus consumers are able to buy animal products at lower and lower prices and in this part of the world there is no shortage of animal products. This development has had its price, and to a great extent that price has been paid by the animals. Thus the animals typically get less space per individual than they did previously; and they live in barren environments that do not allow them to exercise their normal range of behaviors. The intensive breeding schemes that enable each generation of animals to produce meat, milk or eggs faster and with a lower input of feed have been accompanied by increased problems with production diseases.

Production diseases do not only constitute a problem for the animals which fall victim to these diseases. They also constitute a cost to the farmer and the cost may at the end of the day be imposed on the consumers. Therefore from a purely human centred point of view there may be good reasons to try to fight production diseases. However, sometimes the cost of fighting production diseases may be higher than the gain - and therefore it may from an economic point of view be most efficient to accept a certain level of disease. An example is the high incidence of leg problems in broilers. Since breeding with the aim of making a dramatic decrease in leg problems will have as a consequence that there will be less progress in growth rate it seems to pay off to accept a high level of leg problems. Thus in some cases there will be a dilemma between on the one hand economic efficiency and on the other hand preventing or curing production diseases. There is no consensus on how to tackle this dilemma. One extreme is the view taken by adherents of the so-called animal rights view. According to this view we are never justified in harming animals for human purposes. The other extreme is the ruthless view according to which animals are there to be used at our discretion.

However, most people have a view which covers the middle ground between these two extremes. It is accepted that animals may be used for production - contrary to the animal rights view. However, contrary to the ruthless view, it is only accepted under certain conditions. The aim of this presentation is to present different ethical perspectives on what is acceptable to use animals for production and in particular what is an acceptable level of production diseases. 